\author{
Carlos Magno Gomes \\ Universidade Federal de Sergipe
}

\title{
O femicídio na ficção de autoria feminina brasileira
}

\begin{abstract}
Resumo: Este artigo'apresenta um estudo sobre as representações da violência de gênero, com ênfase no femicídio - homicídio de mulheres -, nas narrativas contemporâneas brasileiras. Analisa-se como a violência de gênero e o femicídio são construídos em "A língua do p (1974)", de Clarice Lispector, e "Venha ver o pôr do sol" (1970), de Lygia Fagundes Telles. Essas narrativas descrevem as sutilezas da violência simbólica, a agressividade da violação sexual e a brutalidade do assassinato premeditado, respectivamente. Metodologicamente, parte-se das diferentes abordagens das ciências sociais e das teorias feministas acerca da "Lei Maria da Penha" e da violência de gênero, propostas por Constância Lima Duarte, Lia Zanotta Machado e Rita Laura Segato.
\end{abstract}

Palavras-chave: violência de gênero; femicídio; estupro.

Copyright (c) 2014 by Revista Estudos Feministas.

1 Este artigo é resultado de parte da pesquisa desenvolvida durante estágio de pós-doutorado realizado no Programa de Pós-graduação em Estudos Literários da UFMG, sob a supervisão da Profa. Dra. Constância Lima Duarte, entre 2012 e 2013.

${ }^{2}$ Neste artigo, vamos utilizar o neologismo "femicídio" - homicídio de mulheres-relacionando-o tanto aos crimes que acontecem no espaço doméstico como aos que acontecem no espaço público, conforme Lia Zanotto Machado (2006, p. 15) Cabe registrar que esse termo pode ser empregado com sentido mais amplo; conforme Rita Laura Segato (2006, p. 11), os "feminicídios" não são "crimes comuns", são crimes que poderiam ser denominados de segundo Estado ou de corporação e têm uma dimensão genocida como os registrados no México por mafiosos em Ciudad Juárez.
O homicídio de mulheres na história da literatura brasileira recebeu um tratamento diferenciado na década de 1970 nos textos de autoria feminina. Nesse período, diversas escritoras passaram a questionar diferentes formas de violência de gênero e abriram espaço para a representação do femicídio - homicídio de mulheres - como resultado de relacionamentos afetivos mal resolvidos e como consequência de violência sexual. ${ }^{2}$ Esses crimes passaram a ser punidos com mais rigor a partir da Lei 11.340/2006, conhecida como "Lei Maria da Penha", que tem como objetivo criar mecanismo para coibir a violência doméstica e familiar contra a mulher. Além de buscar o fim da impunidade de crimes que, até bem pouco tempo, eram tidos como parte da dinâmica familiar, como cárcere privado, agressões físicas e psicológicas, essa lei pode ser usada como um novo horizonte de expectativa extraliterário para a interpretação de textos literários.

Dentro da história da literatura brasileira, Constância Lima Duarte ressalta dois tipos de violência doméstica: a simbólica e a física. No primeiro caso, ela destaca como exemplo Laços de família (1960), de Clarice Lispector, que 
${ }^{3}$ Constância Lima DUARTE, 2010 p. 229.
${ }^{4}$ Guita Grin DEBERT e Maria Filomena GREGORI, 2008, p. 173.

${ }^{5}$ Lia Zanotta MACHADO, 2010, p. 69. descreve a mulher diante da imposição de normas e valores que tornam invisíveis a violência, que pode parecer imperceptível em algumas relações, mas humilha, magoa, e suas marcas reverberam por muito tempo dentro da mulher; no segundo, essa crítica feminista destaca os textos de autoras de ascendência afro-brasileira, como Conceição Evaristo. Tais textos nos sugerem "releituras da violência, expondo sem melindres de personagens-chagas o cotidiano feminino." ${ }^{3}$

Com uma proposta de ampliar essa tipologia sugerida por Constância Lima Duarte para as representações de violência de gênero na literatura brasileira, acrescentamos o femicídio como uma categoria relevante para se estudar a violência contra a mulher, visto que o número de obras que tratam desse crime é amplo e merece mais atenção da crítica literária. Como exemplos iniciais, podemos citar obras reconhecidas em que esse tema está presente: A maçã no escuro (1954), de Clarice Lispector, "Sangue esclarecido" (1973) e Vozes do deserto (2004), de Nélida Piñon, e O matador (1995), de Patrícia Melo, entre tantas outras. Essa lista traz diferentes contextos históricos e sociais que acrescentam novos sentidos para o homicídio de mulheres na história da literatura brasileira. Partindo da exploração dos conceitos de crimes contra a mulher propostos pela "Lei Maria da Penha", este artigo faz um recorte para o estudo da representação do femicídio em Clarice Lispector e Lygia Fagundes Telles. Didaticamente, dividimos nossa abordagem em dois momentos: no primeiro, exploramos a complexidade que perpassa a utilização de alguns conceitos referentes à violência de gênero e ao femicídio conforme o debate proposto por Lia Zanotta Machado e Rita Laura Segato; no segundo, construímos uma reflexão acerca de como a violência sexual e o femicídio estão representados em "A língua do 'P'” (1974), de Clarice Lispector, e de como o femicídio é narrado quando o homem se sente abandonado em "Venha ver o pôr do sol" (1970), de Lygia Fagundes Telles.

Antes de seguirmos na análise, cabe assinalar que, apesar de a "Lei Maria da Penha" ter como meta o fim da impunidade masculina, ela tem gerado controvérsias sobre sua aplicabilidade, pois ainda não está em prática como foi planejada. Além disso, há conflitos interpretativos que deixam o assédio sexual fora da guarida dessa lei, posto que a violência de gênero é subsumida ao espaço doméstico e à esfera familiar. ${ }^{4}$ Mesmo assim, sua importância é indiscutível para o avanço dos direitos das mulheres em situação de perseguição no espaço da casa, pois leva em conta o combate às violências relacionais às questões de gêneros que vêm de longa duração. ${ }^{5}$

Nesse caso, ressaltamos que a "Lei Maria da Penha" luta contra o senso comum, herança atávica da sociedade 
${ }^{6}$ Heleieth I. B. SAFFIOTI, 1999, p. 88.

${ }^{7}$ DEBERT, GREGORI, 2008, p. 176

${ }^{8}$ Elódia XAVIER, 2007, p. 22. patriarcal, na qual "o próprio gênero acaba por se revelar uma camisa de força: o homem deve agredir, porque macho deve dominar a qualquer custo; e mulher deve suportar agressões de toda ordem, porque seu 'destino' assim determina". ${ }^{\circ}$ Com isso, o debate sobre as propostas de intervenção e os conflitos gerados com a aplicação dessa lei nos alerta para a importância de rejeitarmos a premissa de que, por fazerem parte do espaço privado da casa, alguns tipos de violência são aceitos como parte da cultura. Todavia, para rompermos com esse paradigma ainda presente em muitas regiões do país, precisamos continuar atentos à "tipificação de abusos, à definição das circunstâncias envolvidas nos conflitos e à resolução destes no plano jurídico".? Dessa forma, mesmo com os problemas enfrentados pela aplicação da "Lei Maria da Penha", sua criação tonar-se uma nova referência cultural para análise e tipificação dos crimes próprios da violência doméstica.

Em estudo sobre a representação do corpo feminino na ficção brasileira, Elódia Xavier destaca o cuidado que a escritora brasileira tem em questionar as regras de gênero, próprias da família patriarcal. Essa pesquisadora identifica diversas formas de representação do corpo feminino que problematizam as regras sociais de submissão do corpo da mulher à opressão masculina. Entre os corpos, que não aceitam o jogo masculino da opressão, estão o "violento" com o qual a mulher rejeita o processo de dominação e passa a defender com agressividade sua integridade física - e o "liberado" - por meio do qual a mulher expressa a liberdade como mentora de sua vida social e psíquica. ${ }^{8}$ Com tal análise, essa pesquisadora ressalta o quanto a escritora brasileira no século XX teve preocupação em questionar as regras do patriarcado, enquanto buscava novas identidades fora do espaço da família tradicional.

Em um estudo que leva em consideração as relações entre literatura, feminismo e mudanças sociais, Constância Lima Duarte apresenta quatro momentos históricos em que o feminismo contribuiu para a mudança de valores na sociedade brasileira: a produção de Nísia Floresta sobre os direitos das mulheres; o surgimento de jornais e revistas voltados para o público feminino a partir de 1870; a mobilização da mulher pelo voto e pelos direitos iguais para todos no início do século XX; e, por último, sobretudo em plena ditadura militar, a luta feminista pela liberdade do corpo da mulher, pelo controle da maternidade, por sua independência financeira e contra a censura e a violência de gênero. ${ }^{9}$

Assim, tanto os estudos de Constância Duarte como os de Elódia Xavier vêm mapeando as estratégias de resistência exploradas na literatura de autoria feminina contra as diferentes formas de violência de gênero e pela dos direitos 
10 SAFFIOTI, 1999

"DEBERT E GREGORI, 2008.

12 DEBERT e GREGORI, 2008, $p$ 170.

${ }^{13}$ Rita Laura SEGATO, 2003, p. 2.

14 Judith BUTLER, 2003, p. 29 da mulher. Por meio de diferentes abordagens, essas pesquisadoras constatam que a escritora brasileira aos poucos vai deixando o prisma do sujeito universal de lado para defender o lugar de fala da mulher segundo as subjetividades e particulares de suas performances de gênero que deslocam os paradigmas sociais. Por tais constatações, a seguir, fazemos uma reflexão acerca de alguns conceitos sobre violência de gênero e femicídio.

\section{Entre crimes e reflexões teóricas}

Nessas últimas décadas, o feminismo tem buscado diferentes ferramentas teóricas para analisar o fenômeno da violência de gênero, que vão do entendimento desse delito como parte da questão estrutural do patriarcado, como nos sugere Saffioti, ${ }^{10}$ à relativização do papel da mulher como vítima da violência, conforme Debert e Gregori." Nesse território de diferentes abordagens, tem se sobressaído a perspectiva de que a noção de dominação patriarcal torna-se insuficiente para se entender o fenômeno da violência contra a mulher, visto que as relações de gênero não são estáticas.

Essa mudança de paradigma na interpretação da violência doméstica se deu a partir da análise das queixas e dos depoimentos de mulheres que, por meio de recursos simbólicos, tentavam negociar as suas relações na família. ${ }^{12}$ Portanto, a relativização dos papéis masculinos e femininos nas situações de violência tem proporcionado uma reflexão teórica mais apropriada aos fenômenos sociais atuais. Em comum, as diversas perspectivas feministas, que compreendem da vitimização à violência como forma perversa de comunicação, reconhecem que a violência de gênero pode ser a física, a psicológica, a sexual e a estrutural, reproduzida pela discriminação de gênero nos campos econômicos e sociais. ${ }^{13}$

Diante desses diferentes aspectos que envolvem o processo de interpretação da violência contra a mulher, cabe conceituarmos o que estamos denominando de violência de gênero. Partimos das constatações presentes em diversas áreas de estudo que reconhecem que o poder perpassa a performance de gênero, que é uma relação socialmente construída entre homens e mulheres e serve como categoria de análise para se investigar a representação do feminino e do masculino, visto que a identidade de gênero não é preestabelecida, pois é sempre "deslocada pelas posições históricas e antropológicas que compreendem o gênero como uma relação entre sujeitos socialmente construídos, em contextos especificáveis". ${ }^{14} \mathrm{Na}$ construção social, a violência de gênero pode ser identificada quando se atribui simbolicamente ao feminino uma posição inferior, na qual a mulher 
${ }^{15}$ MACHADO, 2010, p. 62.

${ }^{16}$ DEBERT, GREGORI, 2008, p. 167.

17 BUTTLER, 2003 p. 29

18 DEBERT e GREGORI, 2008, p. 177.

19 MACHADO, 2010, p. 57. passa a ser vítima preferencial e crônica da opressão física, moral ou sexual de um homem. ${ }^{15}$ Cabe ressaltar ainda que, por analisar textos que se referem tanto ao ambiente doméstico como ao espaço social, acreditamos que o conceito "violência de gênero" seja o mais apropriado. Além disso, esse conceito é usado para relativizar a questão da passividade feminina, visto que, nos estudos que têm como referência o sistema de justiça, não se aceita mais a mulher como vítima passiva da dominação. ${ }^{16}$

No contexto familiar, a violência de gênero, em alguns casos, está relacionada à necessidade de controle e vigilância de alguns homens que se sentem incomodados pelo sucesso social da companheira. Nesse caso, a violência doméstica tem características comuns nas várias classes sociais e regiões do país. A mulher é vítima não só de um agressor, mas de uma prática cultural. Há diferentes tipos de violências simbólicas e físicas que fazem parte da intimidade do casal. Estão entre elas, xingamentos, empurrões e surras que causam lesões corporais graves. Nesse contexto, as dependências econômica, física e afetiva se confundem em muitos casos dos conflitos familiares, complicando a situação da vítima que aceita fazer parte do jogo de violência por interesses particulares.

Dessa forma, destacamos o fato de a flexibilidade da identidade de gênero não ser reconhecida pelo agressor masculino, configurando-se em um dos motivos geradores da discórdia entre os gêneros. Nesse jogo em que a construção da identidade se constrói "no e através do outro", podemos melhor relativizar as questões de poder que sustentam 0 gênero como "conjuntos específicos de relações, cultural e historicamente, convergentes". ${ }^{17}$ Esse aparato regulatório que governa o gênero cria um regime "disciplinar" próprio que precisa ser melhor analisado, pois a mulher, em situação de perigo, tem seus limites diante de um homem agressor. O que não podemos mais é simplificar nossas análises, repetindo o discurso da vitimizada, visto que as dicotomias tornam-se enfraquecidas "porque supõem uma coerência a cada termo da oposição, inexistente na dinâmica que constitui as representações e as relações sociais". ${ }^{18}$

Lia Zanotta Machado, a partir de depoimentos de homens agressores em Brasília, ressalta que, em muitos casos, a violência de gênero está relacionada à defesa da honra masculina. A busca do controle e a manutenção da ordem fazem parte da violência de gênero, pois, "em nome do controle, do poder e dos ciúmes, os atos tendem a ser de violência cotidiana e crônica, física, psíquica. Podem e desencadeiam em morte". ${ }^{19}$ Trata-se de uma violência cujo agressor é um parceiro com o qual a mulher mantém ou manteve alguma estabilidade afetiva, visto que quase $77 \%$ 
${ }^{20}$ MACHADO, 2006, p. 15.

${ }^{21}$ SEGATO, 2006, p. 6.

${ }^{22}$ MACHADO, 2010, p. 77.

${ }^{23}$ MACHADO, 2010, p. 76.

${ }^{24}$ SEGATO, 2003, p. 8. dos assassinatos de mulheres são cometidos por homens abandonados. Para piorar esse quadro, na grande maioria das vezes, tal crime é antecedido por agressões físicas e sexuais. Portanto, "os femicídios são 'domésticos' e se traduzem no ponto final da escalada desta violência doméstica cotidiana". ${ }^{20}$

Na perspectiva antropológica, o femicídio está entre os crimes que têm uma fundamentação simbólica de desprezo pelo corpo feminino, por isso valores culturais devem ser incluídos no processo de análise desse crime. Tanto nas formas de violência familiar como nas urbanas, o corpo da mulher é punido por ter contestado e se projetado fora do padrão masculino de dominação. O homicídio, nesses casos, pode ser entendido como parte de normas culturais que impõem formas de controle ao corpo da mulher, visto que a significação territorial da corporalidade feminina é fundamentada por normas pertencentes à ordem moral. ${ }^{21}$

Tal constatação pode ser identificada na fala de agressores ouvidos por Lia Zanotta Machado, que justificam seus crimes conforme a relativização da ordem moral. Nesses casos, é senso comum justificar a violência contra a mulher pelo direito ao prazer do corpo feminino; ou, no caso de estupradores condenados, pelo erro que cometeram de sair só, como constata Machado: "se algum erro cometeram, entendem que seu ato já está reparado, porque "ela também errou" ao "vagabundear" por "altas horas". ${ }^{22}$ Seguindo uma proposta teórica interdisciplinar, passamos a análise da representação da violência de gênero e do femicídio na ficção de Clarice Lispector e Lygia Fagundes Telles.

\section{O homicídio como sacrifício do estupro}

No espaço social, a violação do corpo da mulher é tida como crime, sendo esse ato reconhecido pelo senso comum "como um ato desumano, inumano, inconcebível", apesar de praticado com frequência. ${ }^{23} \mathrm{~A}$ relação entre o reconhecimento da desumanidade do estuprador e a recorrência desse crime é uma constatação que choca, pois, se ele é tão perverso e "sujo", por que tantos homens ainda o praticam? Para além desse imponderável absurdo, muitos estupros são seguidos do homicídio da mulher, o que dificulta ainda mais qualquer tipo de análise lógica. Rita Segato ressalta que o ato de violação do corpo feminino é próprio da estrutura de gênero que empurra a mulher para os sombrios territórios do sacrifício. ${ }^{24}$ Tal ato, que duplamente rebaixa o corpo da muIher, foi narrado por Clarice Lispector, de forma particular, em "A língua do 'P'”, da coletânea A via crucis do corpo (1974).

Esse conto traz o sacrifício da vítima como um ato gratuito do desejo de violação do corpo feminino. No plano 
ficcional, Clarice Lispector investe os valores sociais, ao construir uma personagem que se vulgariza para escapar das fantasias sexuais de dois ladrões. Essa narrativa apresenta uma perspectiva estética híbrida de ficção e jornalismo. Com isso, as fronteiras entre texto e contexto social violento ficam mais explícitas. Como se trata de uma obra encomendada, sua temática gira em torno da sexualidade humana. Particularmente, a autora brinca com as fantasias sexuais de homens e mulheres e satiriza a opressão sexual como parte da violência social. No conto em destaque, a mulher se depara com o imprevisível desejo masculino de sexo e violência.

Assim, "A língua do 'P'" traz o tema do femicídio como parte da violência urbana e relativiza o papel da mulher diante do agressor sexual. A violência física e a banalização do crime são expostas como partes do mesmo problema. Essa violência se inicia com o assédio sexual de Cidinha, a protagonista, e é finalizada com o estupro e o femicídio de outra mulher. Ao trocar a vítima dos homicidas, Clarice Lispector deixa uma pista do quanto esse crime também é fruto da dominação masculina. O conto apresenta duas perspectivas: a externa, referente ao abuso sexual; e a interna, própria de angústia, do horror e do medo por que passa a personagem. Esses dois movimentos narrativos são importantes para entendermos o quanto essa violência provoca distúrbios emocionais nas vítimas.

O conto contrasta a violência sexual com a virgindade de Cidinha, uma "professora de inglês" que entra em choque com a descoberta de que irá ser abusada sexualmente por dois estranhos, em um trajeto entre Minas Gerais e o Rio de Janeiro, que passam a assediá-la por meio de uma linguagem cifrada, a língua do 'P'. Como Cidinha entendia a linguagem que eles usavam, entrou em pânico no primeiro momento. Ao traduzir o diálogo entre os dois algozes, ela passa a temer: "queriam dizer que iam currá-la no túnel... O

${ }^{25}$ Clarice LISPECTOR, 1998, p. 68.

${ }^{26}$ LISPECTOR, 1998, p. 68.

${ }^{27}$ MACHADO, 2010, p. 78.

${ }^{28}$ LISPECTOR, 1998, p. 69. que fazer? Cidinha não sabia e tremia de medo". ${ }^{25}$ Além do terror do ato sexual violento, eles ameaçavam matá-la: "Se resistisse podiam matá-la. Era assim então". ${ }^{26}$ Nesse caso, o texto ficcional joga com conceitos sociais do senso comum, pois, para a maioria dos entrevistados por Lia Zanotta Machado, os estupradores preferem as mulheres de "vida fácil", visto que "as vadias e prostitutas não teriam direito de dizer não". ${ }^{27}$

Como saída, Cidinha traça um plano para se livrar daquele destino trágico. Na sua angústia, pensou: "se eu me fingir de prostituta, eles desistem, não gostam de vagabunda" ${ }^{28}$ Essa troca de papéis, pensada por Cidinha, assinala o quanto o corpo da prostituta é desvalorizado no contexto social e nos remete ao jogo ficcional proposto pela autora da quebra dos valores tradicionais. A questão de classe e aparência da vítima, Cidinha, reforça a perversão 
${ }^{29}$ SEGATO, 2003, p. 3.

${ }^{30}$ LISPECTOR, 1998, p. 69.

${ }^{31}$ MACHADO, 2006, p. 14

${ }^{32}$ LISPECTOR, 1998, p. 70.

${ }^{33}$ MACHADO, 2010, p. 76.

${ }^{34}$ MACHADO, 2006, p. 15 e o sadismo que motivam o estupro e o desapego ao corpo da mulher com o femicídio. No campo social, simbolicamente tal representação traz à tona um desprezo universal pelo corpo feminino como identificado por Rita Laura Segato, que, analisando a mistificação do feminino em diferentes sociedades, constatou uma contradição universal construída como faces de uma mesma moeda: a valorização do feminino e os dados alarmantes de violência contra a mulher em escala mundial. ${ }^{29}$

Além da tentativa de estupro, Cidinha passa por uma via crucis da violência cultural que não favorece a denúncia desse crime. Mesmo estando em espaço público e tendo testemunhas, essa personagem teve que fazer um malabarismo performático para se salvar. Apesar da violência verbal, ela se salva após se exibir com gestos sensuais e decote lascivo. Como consequência, dessa mudança de postura ela passa a ser rejeitada pelos criminosos, todavia passa a ser punida, pois foi expulsa do trem e entregue para a "polícia na primeira estação" ${ }^{30}$ Nesse caso, a invisibilidade da agressão está presente na omissão do bilheteiro, do maquinista e na forma como a polícia age. Portanto, a atmosfera absurda do conto também nos remete a uma sociedade de regras aviltantes ao desrespeito aos direitos da mulher. Essa cultura da violência é fundada por meio de uma construção simbólica que reforça uma "construção hegemônica dos valores do masculino" que "se faz em torno do desafio da honra, do controle das mulheres e da disputa entre homens". ${ }^{31}$

Depois de presa três dias por comportamento desrespeitoso, Cidinha pôde, enfim, seguir sua viagem de cara lavada, mas toda aquela humilhação lhe trouxe uma profun-da angústia existencial. Ela passou a se sentir deprimida e confusa, visto que também ainda era virgem. Para piorar sua tristeza, ficou sabendo, por meio de uma manchete de jornal, que o homicídio, planejado contra ela, acontecera com uma desconhecida. Essa constatação a deixou mais insegura, mas preferiu seguir sua viagem após ler: "Moça currada e assassinada no trem". ${ }^{32}$ Se Cidinha precisou atravessar um processo de purificação pela ameaça da violência sexual que teve que enfrentar, seus algozes ficaram livres. No campo social, isso não é muito diferente, os estupradores, mal se distanciam da cena de estupro, voltam às atividades cotidianas, sem recorrer a nenhum ritual de purificação ou de reintegração. ${ }^{33}$ Além disso, o conto retrata um ato sexual de violência muito comum na vida urbana, pois, não satisfeitos de explorarem suas vítimas, ainda tiram suas vidas para não serem denunciados. Lia Zanotta Machado destaca que o assassinato é parte do ritual em que prazer e sadismo macabro se confundem, pois o abuso sexual é usado como um meio para o femicídio, resultado final da violência física contra a mulher. ${ }^{34}$ 


\section{Um crime premeditado}

Diferente do crime executado por desconhecidos, o femicídio, quando nasce da violência doméstica, é a parte macabra do um processo de brigas e desavenças pessoais em que diferentes interesses estão em jogo entre um homem e uma mulher. Em "Venha ver o pôr do sol”, Lygia Fagundes Telles apresenta uma atmosfera de mistério e um tom sombrio próprio das narrativas policiais ao descrever a cilada montada por Ricardo para se vingar de sua ex-namorada. $O$ espa-ço do cemitério decadente e abandonado reforça o suspense que envolve o encontro do casal, antecedido por chantagens e manipulações. Desesperado, Ricardo "implora um último encontro" e, para isso, "atormenta dias seguidos"

${ }^{35}$ Lygia Fagundes TELLES, 1999, p. 127.

${ }^{36}$ TELLES, 1999, p. 125.

${ }^{37}$ BUTLER, 2001, p. 154.

${ }^{38}$ TELLES, 1999, p. 128

${ }^{39}$ TELLES, 1999, p. 127
Raquel, convencendo-a de mais uma chance. ${ }^{35}$ Todavia, nas sombras do cemitério, Ricardo deixa claro que se sente rejeitado por ter sido trocado por um homem com uma posição social melhor que a dele. Inconformada com aquele local ermo, Raquel tenta mudar o roteiro do passeio, ao propor pagar a ida para outro lugar, mas Ricardo logo lhe lembra: "Com o dinheiro dele? Prefiro beber formicida". ${ }^{36}$

Com a argumentação que não tinha dinheiro, Ricardo consegue convencê-la a ir mais adiante com leves empurrões e muita insistência. Com o desenrolar da narrativa, percebemos que um dos motivos do descontrole de Ricardo é a liberdade de Raquel. Ele não aceita que ela tenha sucesso e seja livre para escolher o companheiro que ache mais justo. Ricardo não reconhece que a performance de gênero de Raquel é própria de uma mulher que busca novos conceitos identitários, visto que propôs "instabilidades" e ressignificação do seu próprio conceito de mulher que se volta contra a lei regulatória, gerando "rearticulações" e colocando em questão a identidade hegemônica. ${ }^{37}$

Na conversa entre os dois, percebemos que a busca por mudanças, como o novo relacionamento, é prioridade para a vida de Raquel, no entanto Ricardo se mostra preso a uma ideia de relação fixa, que não existe mais. Quando ele faz referência ao relacionamento dos dois, defende apenas o seu ponto de vista: "E eu te amei. E te amo ainda. Percebe a diferença?". ${ }^{38}$ Ao tentar impor seu amor incondicional como uma norma para o relacionamento, observamos que se trata de um sujeito que não aceita a mobilidade identitária de Raquel e passa a enxergar no corpo dela um corpo que pesa, por não se enquadrar em seu padrão identitário. Aos poucos, Ricardo reforça sua mágoa por ter sido abandonado pela sua condição social quando a descreve como interesseira e dissimulada: "A boa vida te deixou preguiçosa? Que feio - lamentou ele, impelindo-a para frente". ${ }^{39}$ Com tal postura, ele dissimula seu sentimento de rejeição e de desonra 
40 TELLES, 1999, p. 130.

${ }^{41}$ TELLES, 1999, p. 130.

42 MACHADO, 2010, p. 14.

${ }^{43}$ TELLES, 1999, p. 131.

${ }^{44}$ TELLES, 1999, p. 131

${ }^{45}$ SEGATO, 2006, p. 6. social, mas não consegue esconder que não se sente satisfeito com a mudança identitária dela. Como justifi-cativa final para chegarem a um ponto mais afastado da entrada do cemitério, Ricardo inventa que estão indo visitar o túmulo familiar, onde sua mãe e prima estão enterradas.

Assim, em "Venha ver o pôr do sol", a violência de Ricardo vai aumentando à medida que ele se não consegue impor seu amor. Nessas cenas, o crime premeditado vai sendo lapidado por uma mente atormentada pela rejeição que aprisiona a amada em um jazido abandonado. A perversidade por trás das atitudes de Ricardo chega ao ápice quando Raquel descobre que caiu em uma cilada e entra em pânico: "-Seu mentiroso! Brincadeira mais cretina". ${ }^{40}$ Com o aprisionamento de sua ex-namorada, em uma capelinha abandonada, a violência de gênero se concretiza como um plano de assassinato.

Quando Raquel tenta abrir a porta do jazigo, Ricardo executa sua última ação para deixá-la aprisionada: "ele esperou que ela chegasse quase a trocar o trinco da portinhola de ferro. Então deu uma volta à chave, arrancou-a da fechadura e saltou para trás". ${ }^{41}$ Com esse golpe, o crime estava executado, Raquel estava sendo punida por não ter voltado para ele. Esteticamente, podemos interpretar que o conto traz à tona um comportamento social muito comum quando o homem perde o controle do relacionamento. No conto, essa perspectiva pode ser identificada nos mínimos detalhes que vão das chantagens, passando pelos empurrões para que Raquel seguisse em frente até a cena final de ser trancafiada no jazigo. Tais atitudes se aproximam das deduções de Lia Zanotta Machado sobre os motivos dos femicídios como "controle e posse da mulher, desejo de ter, desejo de não perder, desejo de que as mulheres nada queiram a não ser eles mesmos, são o que se pode deduzir das razões dos atos violentos de que nos falam os homens agressores". ${ }^{42}$ Incapaz de prever o sinistro crime que motivou o convite, Raquel desconfia que seja apenas uma brincadeira de mau gosto do ex-namorado: "Me dá a chave desta porcaria, vamos! - exigiu, examinando a fechadura nova em folha. Examinou em seguida as grades cobertas por uma crosta de ferrugem". ${ }^{43}$ Com um narrador que assinala a diferença entre a fechadura nova e a ferrugem da grade, o conto revela os detalhes da vingança do homem abandonado. Depois de presa na capelinha, Raquel passa a ser descrita como um animal: "Durante algum tempo ele ainda ouviu os gritos que se multiplicaram, semelhantes aos de um animal sendo estraçalhado". ${ }^{4}$ Por trás dessa vingança, há o desprezo pelo corpo feminino. Rita Segato, a respeito das estruturas das violências de gênero, assinala que as sanções sobre o corpo da mulher são partes significavas do domínio e potência coesiva de uma coletividade. ${ }^{45}$ 
${ }^{46}$ XAVIER, 2007, p. 132.

${ }^{47}$ DEBERT, GREGORI, 2008, p. 178.
No final, com a descrição inumana que prevalece do corpo feminino, o texto de Lygia Fagundes Telles aproximase da perspectiva simbólica do femicídio como forma de punição. Pela perspectiva sociológica, o corpo feminino de Raquel avultou a ordem masculina de Ricardo, por isso foi rebaixado e aprisionado. Esse corpo degradado também é representado socialmente quando o senso comum vincula a liberdade feminina à promiscuidade. Tal forma de rebaixar o corpo da mulher é respaldada pela cultura ocidental, que desvaloriza o corpo da mulher, pois "com o desprezo pelo corpo cresceu também o desprezo pela mulher". ${ }^{46}$ Dentro desse contexto, observamos que o femicídio pode ser interpretado como parte da cultura da opressão feminina.

\section{Considerações transitórias}

Nessa perspectiva, as novas abordagens feministas acerca da violência doméstica e do femicídio propõem um novo horizonte de expectativa para revisarmos as formas como os textos literários problematizam esses crimes. Como constatado neste artigo, o questionamento dos diferentes tipos de violência contra a mulher, no texto de Clarice Lispector e Lygia Fagundes Telles, faz parte de um projeto intelectual de denúncia de valores que desprezam o corpo da mulher e seu direito de liberdade. Diante dessa postura crítica, essas escritoras trazem à baila o repúdio a toda forma de opressão e violência contra a mulher sem deixar de lado as questões de poder que perpassam a construção da identidade feminina. Apesar de haver violência, suas personagens femininas não são descritas apenas como vítimas, pois conseguem fazer opções e levam em conta "concepções sobre sexualidade, educação, convivência e sobre a dignidade de cada um". ${ }^{47}$

Quanto ao femicídio, este artigo interpretou alguns sentidos da violação do corpo da mulher a partir da violência de gênero. No caso do femicídio, antecedido de estupro, Clarice Lispector vai além ao passear pela seara das fantasias sexuais masculinas e descrevê-las como possessivas e doentias. Em "A língua do 'P'”, essa autora retrata um femicídio como consequência da violência urbana. Ao trocar de papéis, da mulher "certinha" para a prostituta, Cidinha consegue se livrar do estupro, todavia é punida por fazer parte dos corpos abjetos da sociedade. Ironicamente, seu comportamento é censurado e ela é punida por ter se passado por uma mulher sem classe.

Nesse conto, Lispector denuncia diversos aspectos da violência sexual contra a mulher, mas ressalta a falta de punição para o criminoso quando muda os papéis ao colocar a mulher assediada na cadeia e quando debate a 
${ }^{48}$ MACHADO, 2010, p. 81.

${ }^{49}$ DUARTE, 2010, p. 233.

${ }^{50}$ MACHADO, 2006 p. 18. simbolização cultural do estupro como vergonhoso para a mulher. Tal fato torna a denúncia difícil e sugere que o estupro pode ser visto como parte da virilidade em excesso ou como jogos mascarados, como simulacros das relações de desafios, ou até como atos banais. ${ }^{48}$

Em contrapartida, representando o femicídio como parte do contexto familiar, Lygia Fagundes Telles, por meio de uma narrativa de suspense, abre espaço para uma reflexão acerca das atitudes de um homem abandonado. Ao construir uma personagem masculina que planeja se vingar da exnamorada, a autora retoma a representação desse crime de forma inovadora ao descrever uma personagem feminina emancipada. Nesse caso, o femicídio está alinhavado pela manutenção da honra masculina, que opta por eliminar sua companheira, quando essa o abandona.

Nessas obras, a violência contra a mulher é antecedida por questões simbólicas, todavia as autoras não respeitam o senso comum e colocam em tensão essas questões por meio de estratégias estéticas, principalmente, quando ressaltam a possibilidade de a mulher romper com as armaduras de gênero. Nessa perspectiva, vale destacar a força da literatura brasileira de autoria feminina que questiona as diversas formas de violência de gênero, ressaltando o deslocamento social da mulher como oposição à ordem vigente. Além disso, os novos tempos nos pedem que investiguemos como as representações da violência de gênero estão construídas por diferentes autoras que criticam a opressão de gênero e que produzem literatura ao mesmo tempo que constroem um projeto político e social, testemunho e ficção, dando-nos acesso a outras histórias de violências. ${ }^{49}$

No campo social, a punição masculina é uma das saídas para a mudança de paradigma de gênero que está por trás da violência. Com isso, destacamos a importância da "Lei Maria da Penha" como uma estratégia política para a reversão desse quadro de violência. Essa Lei traz a oportunidade de toda a sociedade debater um problema que historicamente esteve silenciado pelas diferentes padronizações culturais, pois "na prática é um lugar propício para o afloramento dos valores de longa duração de uma forma acrítica por muitos operadores de direito". ${ }^{50}$

Nesse sentido, reconhecer a tipificação dos crimes próprios da violência de gênero, conforme sugere a "Lei Maria da Penha", é um primeiro passo para debatermos a impunidade e a subjetividade por trás dos delitos cometidos no espaço privado da família. Reconhecemos que essa Lei não correspondeu ao esperado, no sentido de reverter abruptamente o número de mulheres agredidas por seus companheiros e assassinadas no Brasil. Todavia, as denúncias aumentaram, e o debate em torno desse tema tem motivado diferentes 
${ }^{51}$ SEGATO, 2003, p. 04 setores da sociedade brasileira a lutarem para $\circ$ fim das impunidades.

Concordamos com as críticas, pois sabemos que não se erradica a violência apenas com uma nova lei, visto que "é necessário uma reforma dos afetos constituintes das relações de gênero"51 e uma vontade coletiva de aceitar as novas configurações de gênero para além do controle e da punição do corpo da mulher. Com isso, finalizamos este artigo, lembrando que ainda há muito para ser alcançado na luta pelos direitos das mulheres no Brasil, pois basta lembrarmo-nos das desigualdades de gênero no que se refere ao salário mais baixo e na representação desigual em cargos políiticos.

\section{Referências}

BUTLER, Judith. "Corpos que pesam: sobre os limites discursivos do 'sexo'”. In: LOURO, Guacira. O corpo educado: pedagogias da sexualidade. Tradução de Thomaz Tadeu da Silva. 2. ed. Belo Horizonte: Autêntica, 2001, p. 151-172. Problemas de gênero. Tradução de Renato Aguiar. Rio de Janeiro: Civilização Brasileira, 2003.

DEBERT, Guita Grin; GREGORI, Maria Filomena. "Violência e gênero: novas propostas, velhos dilemas". Revista Brasileira de Ciências Sociais, São Paulo: ANPOCS, v. 23, n. 66, p. 165-211, fevereiro, 2008.

DUARTE, Constância Lima. "Pequena história do feminismo no Brasil". In: CARDOSO, Ana Leal; GOMES, Carlos Magno. Do imaginário às representações na literatura. São Cristóvão: Ed. UFS, 2007, p. 127-134.

. "Gênero e violência na literatura afro-brasileira". In: DUARTE, Constância Lima et al. Falas do outro: literatura, gênero, identidade. Belo Horizonte: Nandyala, 2010, p. 229-234.

FUNCK, Susana. O que é uma mulher? Cerrados, Brasília: UnB, 201 1, p. 65-74.

LISPECTOR, Clarice. "A língua do 'P'”. In: LISPECTOR, Clarice. A via crucis do corpo. Rio de Janeiro: Rocco, 1998, p. 67-70.

MACHADO, Lia Zanotta. "Violência doméstica contra as mulheres no Brasil: avanços e desafios ao seu combate". In: BRASIL. Secretaria Especial de Políticas para as Mulheres. Cartilha Violência Doméstica: Protegendo as Mulheres da Violência Doméstica. Brasília: Fórum Nacional de Educação em Direitos Humanos. 2006, p. 14-18. 2010

Feminismo em movimento. 2. ed. São Paulo: Francis,

SEGATO. Rita Laura. "Las estructuras elementales de la violencia: contrato y status en la etiologia de la violência". Série Antropológica, Brasília: Departamento de Antropologia da UnB, p. 1-18, 2003. 
"Que és un feminicidio: notas para un debate emergente". Série Antropológica. Brasília: Departamento de Antropologia da UnB, p. 1-11, 2006.

SAFFIOTI, Heleieth I. B. "Já se mete a colher em briga de marido e mulher". São Paulo em Perspectiva, São Paulo: Fundação SEADE, v. 13, n. 4, p. 82-91, out./dez. 1999. Disponível em: <http://www.seade.gov.br/produtos/spp/v13n04/ v13n04_08.pdf >. Acesso em: 20 fev. 2013.

TELLES, Lygia Fagundes. "Venha ver o pôr do sol". In: TELLES, Lygia Fagundes. Antes do baile verde. 16. ed. Rio de Janeiro: Rocco, 1999, p. 123-131.

XAVIER, Elódia. Que corpo é esse? O corpo no imaginário feminino. Florianópolis: Mulheres, 2007.

[Recebido em abril de 2013 e aceito para publicação em junho de 2014]

\section{The Femicide in Brazilian Women's Fiction}

Abstract: This work presents a study about the representations of gender violence - focusing on femicide, - in contemporary Brazilian literature. The article analyses how the gender violence and the femicide - the killing of women - are constructed in the short-story "A língua do P" (1974), by Clarice Lispector, and "Venha ver o pôr do sol" (1970), by Lygia Fagundes Telles. These narratives describe the subtleties of the symbolic violence, the aggressiveness of the sexual violence and the brutality of the calculated murder, respectively. Methodologically the study takes the different approaches of the Social Sciences and Feminist Theories concerning Maria da Penha Law and gender violence proposed by Constância Lima Duarte, Lia Zanotta Machado and Rita Laura Segato.

Key Words: Gender Violence; Femicide; Disciplined Body. 